\title{
Plasma Vasopressin During Insulin Withdrawal in Insulin-Dependent Diabetes
}

\author{
J. J. Milles, P. H. Baylis and A. D. Wright \\ Department of Medicine, University of Birmingham, Birmingham, England
}

Summary. Plasma vasopressin was measured in seven insulin-treated diabetics during $24 \mathrm{~h}$ of insulin withdrawal to determine: 1) if abnormalities of the neurohypophysial-renal axis contribute to the dehydration of uncontrolled diabetes mellitus; and 2) the factors causing elevated levels of vasopressin in diabetic ketoacidosis. During the $24 \mathrm{~h}$ period of insulin withdrawal, blood glucose rose from $6.7 \pm 1.0$ to $20.7 \pm 2.4 \mathrm{mmol} / \mathrm{l}$, whereas plasma vasopressin was $3.6 \pm 0.5 \mathrm{pg} / \mathrm{ml}$ initially and in four patients showed little change. Markedly elevated levels of plasma vasopressin $(17.8,19.8$ and $26.6 \mathrm{pg} / \mathrm{ml})$ were observed in three patients following the onset of hypovolaemia, nausea and/or vomiting which are known to stimulate vasopressin release. Free water clearance was negative throughout the study in all patients. Thirst was not noted despite marked hyperglycaemia $(16.9 \pm 2.5 \mathrm{mmol} / \mathrm{l})$ until a significant fall in body weight of $0.9 \pm 0.2 \mathrm{~kg}$ had occurred $(p<0.005)$. We conclude that marked elevation of vasopressin results from non-osmotic stimulation and that the mechanisms of body water conservation are overridden by the glycosuric diuresis.

Key words: Vasopressin, diabetes mellitus, hyperglycaemia, thirst, polyuria

Thirst and polyuria almost invariably occur in uncontrolled diabetes mellitus and have generally been attributed to the osmotic diuresis that occurs when the capacity of the renal tubules to reabsorb glucose is exceeded [1]. The possibility of an inadequate neurohypophysial-renal response to conserve body water was suggested by the observation that hyperglycaemia induced by hypertonic dextrose infusion into normal subjects and insulin-dependent diabetics caused a fall in plasma vasopressin and urine osmolality and failed to induce thirst $[2,3]$. However, several studies have shown that plasma vasopressin is markedly elevated in uncontrolled diabetes mellitus $[4,5]$, and the authors suggested that hypovolaemia, hypotension, nausea and vomiting [3] are the predominant stimuli to vasopressin release in this condition, although osmotic stimulation by unidentified plasma solutes may play a role.

The present study was undertaken to determine: 1) whether suppression of vasopressin with urinary loss of osmotically-free water occurs in the early stages of uncontrolled diabetes mellitus; and 2) the factors that lead to the markedly elevated levels of plasma vasopressin found in the later stages.

\section{Patients}

Seven stable insulin-treated patients, aged 21-39 years (two female) who had no clinical or biochemical evidence of diabetic complications, agreed to take part in the study. The mean duration of diabetes was 8 years (range 2-19 years) and mean $24 \mathrm{~h}$ dose of insulin 53 units (range 32-72 units). Three patients had single morning injections of either a mixture of short and intermediate acting insulin (two patients) or intermediate acting insulin alone; the other four had twice daily doses of mixed short and intermediate acting insulins. None of the patients suffered from diseases other than diabetes or were taking drugs apart from insulin. All the patients were of normal intelligence and had a good understanding of their disease and its acute complications. Consent was obtained only after a detailed explanation of the study and its associated discomfort. The purpose and nature of the study had been approved by the local human research ethical committee.

\section{Protocol}

Patients were admitted at $08.30 \mathrm{~h}$ only having omitted their morning insulin injection (Fig. 1). Intravenous cannulae were then inserted in both forearms one for blood sampling and the other for 


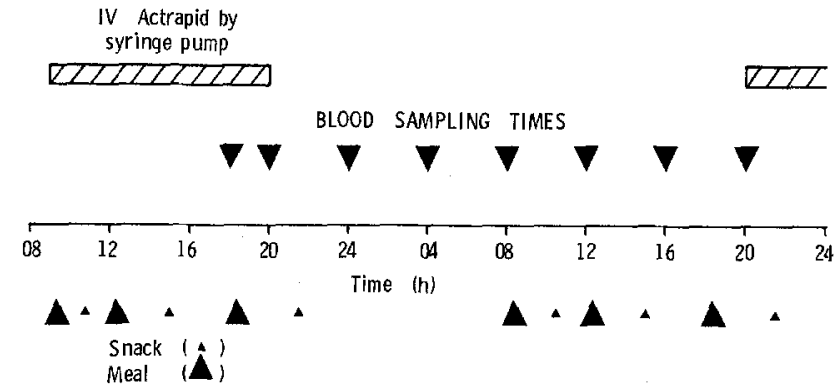

Fig. 1. Protocol for study

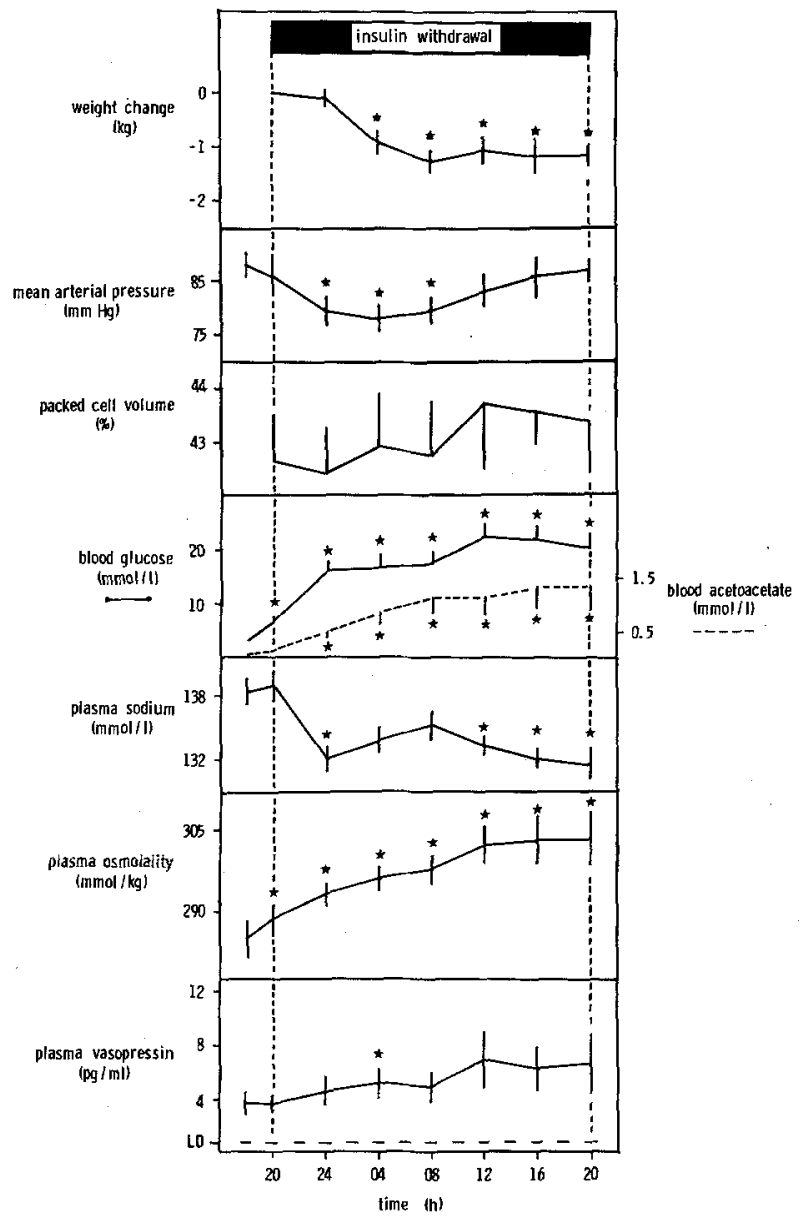

Fig. 2. Changes in plasma vasopressin and factors affecting its release during insulin withdrawal in seven diabetics $12.00 \mathrm{~h}(n=$ $6)$, at $16.00 \mathrm{~h}(n=5)$, and at $20.00 \mathrm{~h}(n=4)$. Asterisks indicate values which differ significantly from basal levels at $20.00 \mathrm{~h}$ (two $p<0.05$ )

administration of a continuous infusion of highly purified porcine (Actrapid) insulin by a syringe pump (Braun) at a rate of $1-5$ units $/ h$, the dose depending on the capillary blood glucose level (Reflomat, Boehringer) which was monitored hourly; higher infusion rates were given during meals. The insulin infusion was discontinued at $20.00 \mathrm{~h}$ for a $24-\mathrm{h}$ period, during which the patients were under constant medical supervision. If any change in the clinical condition of the patient occurred, insulin was recommenced without delay. Patients' activity on the ward was unrestricted, but they were asked to report the development of symptoms such as thirst, nausea, vomiting, pain and faintness, especially when standing. Smoking was not permitted, but the patients were allowed free access to fluids apart from coffee, tea and alcohol. Snacks were taken at $10.30 \mathrm{~h}, 15.15 \mathrm{~h}$ and $21.30 \mathrm{~h}$, and meals at $08.20 \mathrm{~h}, 12.20 \mathrm{~h}$ and $18.20 \mathrm{~h}$, to provide carbohydrate in accordance with the patients' usual prescribed diets. At $4 \mathrm{~h}$ intervals (Fig. 1) after at least $30 \mathrm{~min}$ supine rest, blood pressure was recorded and free flowing venous blood samples were withdrawn into chilled syringes. Patients then emptied their bladders and were weighed. Urine volume was recorded and urine aliquots saved.

\section{Methods}

Blood samples were treated as follows: $1 \mathrm{ml}$ was added to $2.5 \mathrm{ml}$ ice-cold $0.8 \mathrm{~mol} / 1$ perchloric acid for estimation of acetoacetate [6] (detection limit $=0.02 \mathrm{mmol} / 1$ and coefficient of variation $=$ $4 \%) ; 2.5 \mathrm{ml}$ was added to a fluoride tube for glucose estimation (glucose oxidase) and $2.5 \mathrm{ml}$ to a sequestrene tube for haematocrit (Coulter Counter Model-S); the remainder $(30 \mathrm{ml})$ was placed in chilled lithium-heparin tubes, centrifuged at $4{ }^{\circ} \mathrm{C}$ and the plasma frozen at $-20^{\circ} \mathrm{C}$ for estimation of plasma sodium (coefficient of variation $=0.8 \%$ ), urea, osmolality (Advanced Instruments osmometer, model $3 \mathrm{~L}$, coefficient of variation $=0.2 \%$ ) and plasma vasopressin by radioimmunoassay [7] (detection limit $=$ $0.7 \mathrm{pg} / \mathrm{ml}$; intra-assay and inter-assay coefficient of variation = 7.5 and $24.4 \%$, respectively). Urine samples were stored without preservative at $-20^{\circ} \mathrm{C}$ for estimation of osmolality and glucose. Data were analysed by Student's t test and all results expressed as the mean $\pm S E M$.

\section{Results}

All patients tolerated the study well, although the insulin infusion was restarted prematurely in three patients: 19.5 and $23.5 \mathrm{~h}$ after insulin withdrawal in two following the onset of vomiting, and in the third, $12 \mathrm{~h}$ after insulin withdrawal because although asymptomatic, she had become moderately acidotic (pH $7.28, \quad \mathrm{PCO}_{2} 3.8 \mathrm{kPa}$, actual bicarbonate $13.0 \mathrm{mmol} / \mathrm{l}$ ). During the control period on continuous IV insulin, blood glucose was maintained below $10 \mathrm{mmol} / \mathrm{l}$ after $12.00 \mathrm{~h}$ in all patients. After withdrawal of insulin (Fig. 2) blood glucose rose from 6.7 \pm 1.0 to $20.7 \pm 2.4 \mathrm{mmol} / 1$, while plasma sodium fell from $139 \pm 1$ to $132 \pm 2 \mathrm{mmol} / \mathrm{l}$, the greatest changes in both solutes occurring in the first $4 \mathrm{~h}$. Blood acetoacetate rose from $0.07 \pm 0.03$ to $1.33 \pm$ $0.47 \mathrm{mmol} / \mathrm{l}$. Plasma osmolality rose steadily by $14 \pm$ 4 to $303 \pm 5 \mathrm{mmol} / \mathrm{kg}$. Body weight fell by $1.2 \pm$ $0.2 \mathrm{~kg}$ but there were no significant changes in haematocrit. Supine mean arterial pressure (diastolic $+1 / 3$ pulse pressure) fell temporarily during the night. Initially plasma vasopressin was $3.6 \pm 0.5 \mathrm{pg} / \mathrm{ml}$ and 


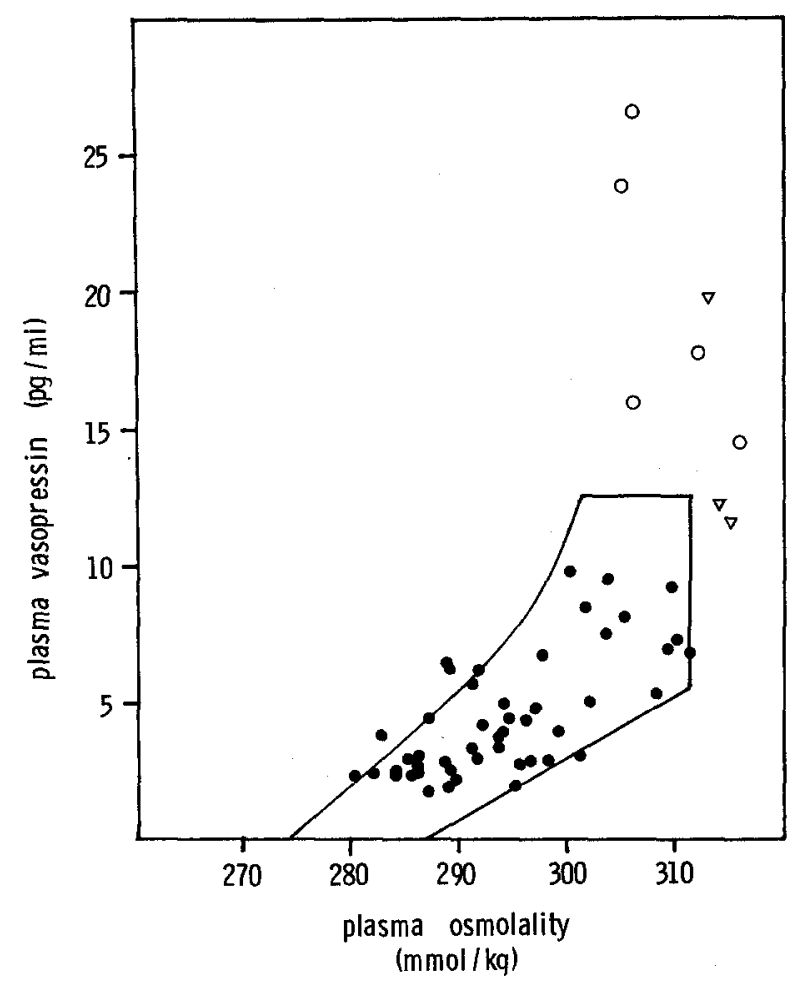

Fig. 3. Relation between plasma osmolality and plasma vasopressin during insulin withdrawal in seven diabetics with $(O$ and $\nabla)$ and without symptoms (-). Boxed area $=$ range in ten normal subjects [8]

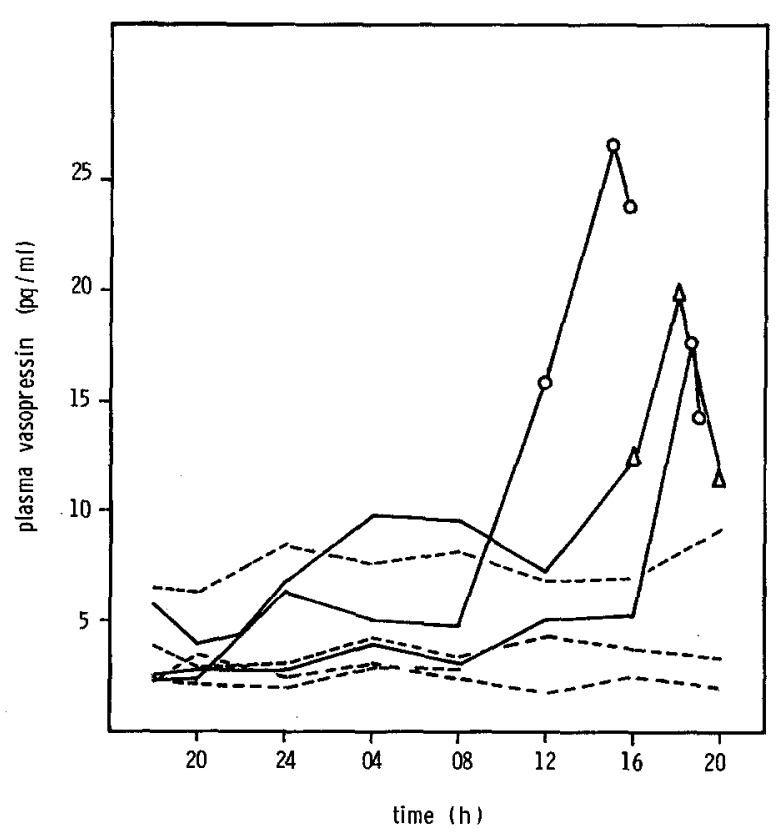

Fig. 4. Changes in plasma vasopressin during insulin withdrawal in seven diabetics with (solid lines) and without symptoms (dashed lines). $O=$ nausea or vomiting; $\Delta=$ postural hypotension at the time of sampling showed little change during the first $12 \mathrm{~h}$ of insulin withdrawal despite the large rise in blood glucose, but rose to $6.6 \pm 2.3 \mathrm{pg} / \mathrm{ml}$ (range $2.0-11.7 \mathrm{pg} / \mathrm{ml}$, $n=4$ ) after $24 \mathrm{~h}$ of insulin lack. High levels of vasopressin falling outside the normal range (Fig. 3) occurred in three patients after the onset of nausea and/or vomiting or symptomatic postural hypotension (fall in systolic blood pressure from 108 to $80 \mathrm{mmHg}$ ). Changes in plasma vasopressin in individual patients are shown in Fig. 4. Urine flow rate (Fig. 5) rose to a maximum of $6.0 \pm 0.9 \mathrm{ml} / \mathrm{min}$ in parallel with the rise in osmolar clearance due to glycosuria. Free water clearance was negative throughout, indicating no urinary loss of osmotically-free water. Total urine output was $4.3 \pm 0.71$ (range 1.4 $6.61)$ and total glucose excretion was $1.1 \pm 0.2 \mathrm{~mol}$ (range $0.4-1.9 \mathrm{~mol}$ ).

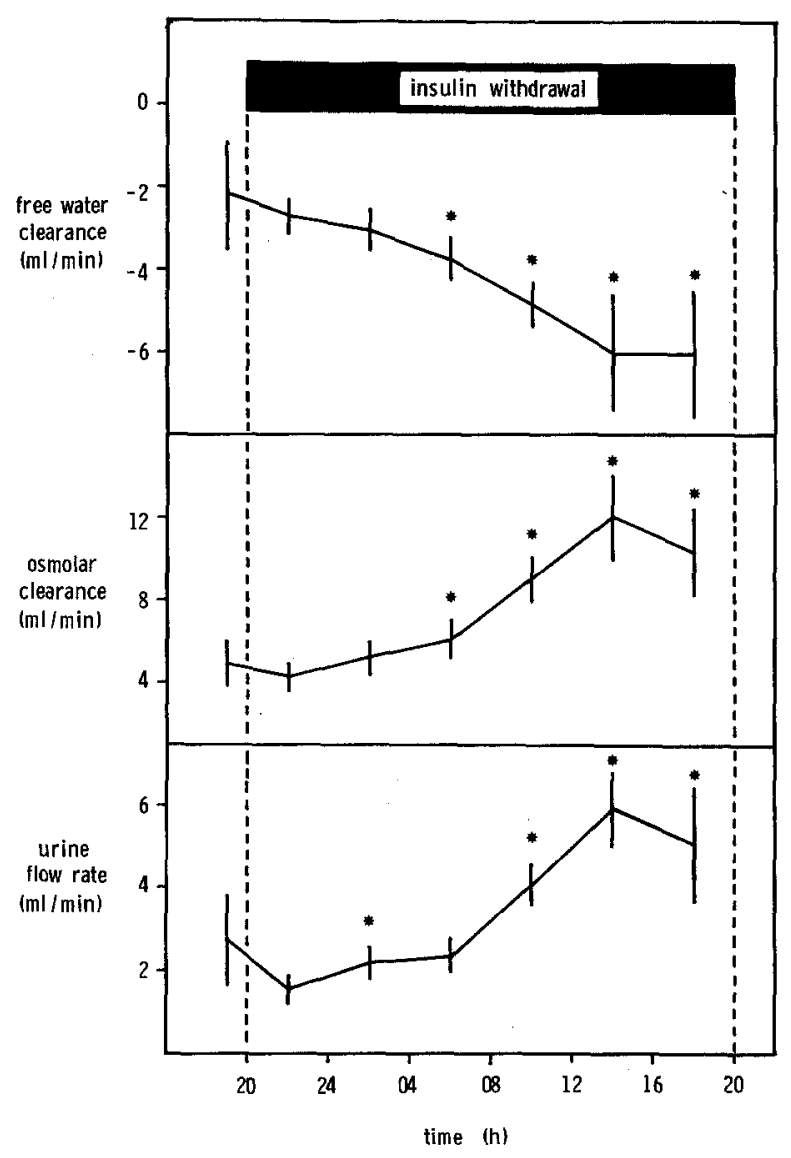

Fig. 5. Changes in free water clearance, osmolar clearance and urine flow rate during insulin withdrawal in seven diabetics. Asterisks indicate valves which differ significantly from basal levels (two $p<0.05$ ) 


\section{Discussion}

It is clear from this study that there is no defect in the neurohypophysial-renal mechanism for water conservation in uncontrolled diabetes mellitus. Plasma vasopressin levels did not fall and were in the range that in normal subjects is associated with maximum antidiuresis [9]. Furthermore, free water clearance was negative throughout the period of insulin deprivation indicating that the renal tubules were responsive to the action of vasopressin. On the other hand, the rising osmolar clearance indicates the diuresis was osmotic due to glycosuria.

The factors that are stimulating vasopressin release require comment. The steady rise in plasma osmolality shown in Fig. 2 was not associated temporally with a similar rise in plasma vasopressin. This might be because the increase in plasma osmolality was largely due to glucose, a solute that does not cause vasopressin release in normal subjects [3] or insulin-dependent diabetics [14], whereas plasma sodium, which is a potent stimulus to vasopressin release [3], showed a predictable fall [10]. The opposite effects of sodium and glucose on vasopressin release are presumably due to differences in the permeability of the blood-brain barrier to these solutes $[3,11]$.

Non-osmotic factors are probably responsible for the high vasopressin levels reported in uncontrolled diabetes mellitus [4, 5], and our results would support this. Small decreases in blood volume alter the response characteristics of the neurohypophysis to changes in body fluid tonicity such that vasopressin is released at a lower threshold of plasma osmolality and increases more for a given rise in plasma osmolality than normal [12]. Although we did not measure blood or extracellular fluid volume directly, we would infer that there was progressive hypovolaemia from the decrease in body weight (Fig. 2) and this might explain why we did not observe a suppressive effect of hyperglycaemia on plasma vasopressin levels. Towards the end of the insulin withdrawal period, three patients had high levels of vasopressin which in each case occurred after the onset of factors known to be potent stimuli of vasopressin release, namely, hypotension, nausea and/or vomiting [3]. Although supine blood pressure was normal at the time of blood sampling in the patient who developed syncopal symptoms, in the absence of neuropathy, postural hypotension indicates an adequate hypovolaemic stimulus to account for his high levels of plasma vasopressin.

Two factors we did not monitor in our study which may affect vasopressin release in uncontrolled diabetes mellitus are the renin-angiotensin system [13] and catecholamines [14].

The effects of elevated levels of plasma vasopressin in uncontrolled diabetes mellitus are controversial but may be twofold. Vasopressin may directly elevate blood glucose in man [15] and high concentrations of vasopressin stimulate glycogenolysis and gluconeogenesis [16]. Our study would not suggest that vasopressin contributed to the degree of hyperglycaemia in the early stage of insulin withdrawal since plasma vasopressin levels fell within the normal range when the greatest change in blood glucose occurred. Secondly, high levels of plasma vasopressin as seen in three of our patients can be associated with a slight pressor response [17].

Thirst was not noted by our patients despite marked hyperglycaemia until $04.00 \mathrm{~h}$ when there had been a fall in body weight of $0.9 \pm 0.2 \mathrm{~kg}(p<0.005$, Fig. 2). Furthermore, hypertonic dextrose infusion in normal subjects does not induce thirst (Milles JJ and Baylis $\mathrm{PH}$ - unpublished observation) and we would, therefore, suggest that hypovolaemia [18] rather than hyperosmolality was the stimulus to thirst in the present study.

In conclusion, this study has clearly demonstrated that suppression of vasopressin does not contribute to the polyuria of uncontrolled diabetes mellitus and elevated levels of vasopressin are likely to be due to non-osmotic stimulation by hypovolaemia, nausea and/or vomiting.

Acknowledgements. We gratefully thank our patients for taking part and the Haematology and Clinical Chemistry Departments, General Hospital, Birmingham, for measuring haematocrit, glucose, electrolytes and acetoacetate. J.J.M. was in receipt of a research grant from the Central Birmingham Health District Trust Funds.

\section{References}

1. Brodsky WA, Rapoport S, West CD (1950) The mechanism of glycosuric diuresis in diabetic man. J Clin Invest 29: 1021-1032

2. Zerbe RL, Vinicor F, Robertson GL (1978) Demonstration of intact osmotic regulation of vasopressin in juvenile onset diabetics. The Endocrine Society. Proceedings of the 60th annual meeting. Endocrinology (Suppl) 102: 225

3. Robertson GL (1977) The regulation of vasopressin function in health and disease. Recent Prog Horm Res 33: 333-385

4. Walsh CH, Baylis PH, Malins JM (1979) Plasma arginine vasopressin in diabetic ketoacidosis. Diabetologia 16: 93-96

5. Zerbe RL, Vinicor F, Robertson GL (1979) Plasma vasopressin in uncontrolled diabetes mellitus. Diabetes 28: 503-508

6. Price CP, Lloyd B, Alberti KGMM (1977) A kinetic spectrophotometric assay for rapid determination of acetoacetate in blood. Clin Chem 23: 1893-1897

7. Baylis PH, Heath DA (1977) The development of a radioimmunoassay for the measurement of human plasma arginine vasopressin. Clin Endocrinol 7: 91-102 
8. Milles JJ, Baylis PH (1979) Plasma vasopressin response to hypertonic saline in normal subjects and patients with polyuria. Clin Sci Mol Med 57: 4p-5p

9. Baylis PH, Heath DA (1978) water disturbance in patients treated with oral lithium carbonate. Ann Intern Med 88: $607-609$

10. Katz MA (1973) Hyperglycaemia-induced hyponatraemia calculation of expected serum sodium depression. N Engl J Med 289: 843-844

11. Aricff AI, Guisado R, Lazarowitz VC (1977) Pathophysiology of hyperosmolar states. In: Andreoli TE, Grantham JJ, Rector FC (eds) Disturbances in body fluid osmolality. The American Physiological Socicty, Bethesda, pp 227-250

12. Robertson GL, Athar S (1976) The interaction of blood osmolality and blood volume in regulating plasma vasopressin in man. J Clin Endocrinol Metab 42: 613-620

13. Share L (1979) Interrelations between vasopressin and the renin-angiotensin system. Fed Proc 38: 2267-2271

14. Schrier RW, Berl T (1975) Nonosmolar factors affecting renal water excretion. N Engl J Med 292: 81-88
15. Suryanarayana BV, Kent JR (1969) Plasma glucose response to natural vasopressin in maturity onset diabetics and adult nondiabetics. Metabolism 18: 241-247

16. Hems DA, Rodrigues LM, Whitton PD (1978) Rapid stimulation by vasopressin oxytocin and angiotensin II of glycogen degradation in hepatocyte suspensions. Biochem $\mathrm{J} \mathrm{172:}$ 311-317

17. Khokhar AM, Slater JDH, Forsling ML, Payne NN (1976) Effect of vasopressin on plasma volume and renin release in man. Clin Sci Mol Med 50: 415-424

18. Fitzsimons JT (1972) Thirst. Physiol Rev 52: 468-561

Received: 19 September 1980

and in revised form: 25 November 1980

Dr. J. J. Milles

General Hospital

Steelhouse Lane

Birmingham $\mathrm{B} 46 \mathrm{NH}$

England 